\title{
Coping with Stress during COVID-19 Using Mind Map: Case Studies
}

\author{
Sahitya, M.G.
}

Tata Institute of Social Science, Balm, Chennai, India

Corresponding author: sahityamg@gmail.com

Received: 09 Jan., 2019

Revised: 21 Feb., 2020

Accepted: 27 March, 2020

\begin{abstract}
Corona Virus turning into global pandemic and countries going under lockdown is taxing. The panorama of not being able to leave house may be distressing, and can negatively impact mental health of the people of any age group worldwide, especially learner community who are at the edge of academic year and looking forward for new endeavours. This uncertainty can lead to anxiety and severe stress. During such time the focus should be on aspects which are in control rather than worrying about what is not in control. It's important for the learners at this stage to handle stress as it can take a toll on him/her both physically and mentally. Besides academic support, they need effective psychological support. Because during stress mind is clustered with several negative thoughts which hamper daily activities and performance. Mastering in 'mind mapping' is skill which could be useful for the learners. The major objective of the paper is to describe the nature of stress the learners can face during this pandemic, provide a framework of mind mapping to cope up with stress to achieve learning outcomes by reducing anxiety, encouraging creative ways to study. This paper will help the teachers and parents to provide effective support to the learners and the learners will be able to develop coping strategies to allocate their energy productively and build resilience against stress. The researcher investigated three case studies using mind map technique. The results show that mind map is one of the useful techniques to reduce stress as it facilitates in visualising all the thoughts and ideas at one place and take further decision by performing those written tasks.
\end{abstract}

Keywords: Coping, COVID-19, Mindfulness, Mind Mapping, Pandemic, Stress

COVID-19 is an infectious disease caused by newly discovered corona virus which started at the end of 2019 in China and subsequently spread all over world. Hence the world is collectively under 
lockdown to prevent spread of this virus. Since there is no vaccination for COVID-19. Social Distancing is considered to be the only solution as of now. Stay home, stay safe, the unexpected lockdown due to corona virus was aimed to fulfill social distancing. Coronavirus outbreak coupled with the lockdown has triggered an increase in the cases of stress and anxiety. Like people of different ages and fields, thestudent population are mostly affected as they are left in the middle ground as their academic activities are paused and are facing ambiguity about future.

Students especially above primary level are supposed to be known as the social butterfly, as this is age for them to explore new things, visit new places, meet new people, try different food and so on. But the present uncertain situation due to COVID-19, unexpected lockdown through the country/world have in a way halted their activities and plans, it seems that the butterflies are again send back to their cocoons. Staying at homes, strictly following advisories, not being able to be connected with all friends, classmates, relatives freely, and getting negative and scary news everyday are sources of stress and this stress could be manifested in their regular life which includes disturbance in sleep pattern, mental fatigue, laziness. Fear of Uncertainty on what next is always oscillating in their minds which may lead to anxiety further developing into stress. Students end up over thinking and their mind is clouded with thoughts hence they won't have a clear vision on where they are leading to which creates confusion in them.

At this stage it is the responsibilities of the educational organizations to provide psychological support along with academic support to the students so that they can handle the stress and anxiety. This paper aims to discuss a technique called 'mind mapping' which can be useful for the learners to handle the stress effectively and to plan for their future endeavors.

\section{REVIEW OF LITERATURE}

Out breaking due to virus affects the routine life of human and their mental health. In March -April, 2009 a new swine influenza virus (S-OIV), A (H1N1), emerged in Mexico and the USA. It spreads quickly world over through human-to-human transmission ${ }^{[1]}$. WHO raised the influenza pandemic alert to the highest level on June, 2009 resulting in outbreaks internationally ${ }^{[2]}$. The authors ${ }^{[3]}$ researched on a cross cultural study of stress and coping among Indian and Canadian students and reported that Indian students experience more stress and prefer emotional focused coping strategies to deal with stress and have external locus of control. Similarly studied ${ }^{[4]}$ the sources of stress and coping strategies among college students and results showed that women were reported with high level of stress as compared to men and use of emotional focused coping dominated for both men and women.

Percival ${ }^{[5]}$ stated that mind mapping is a tool to arrange the thoughts in logical way which helps in managing the task to be performed. It helps to reduce stress when there is more work to do in less time. Trevino ${ }^{[6]}$ reported that the mind mapping group showed significant willingness regarding use of mind map as a creative tool. Application of mind maps with different colours using drawings and encouraging students is known to be the effective strategy for engineering students ${ }^{[7]}$. 
Researchers suggest that too much stress and anxiety creates physical changes in the brain and affect key areas which are involved in memory formation and emotional processing. During stress we may experience the symptoms of poor concentration, forgetfulness and influx of emotion ${ }^{[8]}$.

Some people, either intentionally or unintentionally, employ negative coping strategies to deal with stress. Negative coping strategies can include unhealthy behaviours, distractions, violence, and withdrawal. Unhealthy behaviours such as smoking, drinking alcohol, excessively over/under eating, and drug abuse are sometimes used to relieve stress. Although these strategies can provide temporary stress relief, they can cause more stress in the long run ${ }^{[9]}$. Showing signs of withdrawal such as sleeping, procrastinating, and withdrawing from family, friends, and activities, and disengagement are ways in which people try to remove stress from their lives ${ }^{[8][9]}$.

\section{OBJECTIVES OF THE PAPER}

The paper (i) presents and understanding of stress the learners may suffer from during this pandemic, (ii) provides a framework of mind mapping to cope up with stress to achieve learning outcomes by reducing anxiety, encouraging creative ways to study. (iii) investigate the use of proposed framework for mind map with the help of case studies.

\section{UNDERSTANDING STRESS}

Stress is usually characterised by a sense of feeling overwhelmed. Stress is a feature which gets triggered when there is an undesirable situation. Stress was described "as a relationship between individuals and their environment that is appraised as dangerous and evaluated as beyond their ability to deal with stress". It can have impact on behaviour of people, their communication with others and their overall efficiency. The response for stress by every individual can be identical but the triggering point which creates the atmosphere for stress may vary from person to person.

However, in daily life we often use the term 'stress' to describe negative situation. But it is not true. There are two types of stress: (i) Eustress, which means positive stress (e.g., we experience after exercise); (ii) Distress, refers to negative stress. In this paper we take into consideration the distress which has negative effect on our body and mind.

Keeping the present situation of COVID-19 and lockdown in mind the possible stressor which is affecting the student's mental well-being and health may include- halt on planned future activities, uncertainty about future, Dissociation from natural elements like sunlight, fresh air etc. Social gap and prolonged screen time which is straining for eyes and gives head ache, not being able to adjust to online environment and boredom.

\section{MIND MAP}

Mind map is a tool used to represent thoughts, information in a form of a diagram ${ }^{[10]}$. Usually used for note taking and journalising it is formed around a specific concept, other ideas branching out in a grading 
c) Sahitya

form in order to show association among the two concepts. These branches are considered to be sub topics, thought, different angle etc. which enhances relevance to the map. This helps in brainstorming ideas, visual thinking and problem solving. Majorly used by engineers, educators, psychologist in educational and professional settings. Hence it is considered to be flawless tool for managing stress.

Mind Maps are a boundless way to think outside the box and tackle stress in a unique way. It could be used in various activities like planning for studies, brainstorming or even coming to a conclusion. Similarly,it could also be useful for overcoming external pressures, help to segregate and chunk the ideas. Just like how our brain works when we have an idea, it attempts to branch out different trails of thought associated with the idea. Mind Mapping is a free flow technique, where ideas and key words would flow in as you start building the map. Stress plays a predominant role in an individual life and opting an appropriate approach can help in having a positive impact in order to cope up with it in routine life. It is platform with infinite canvas where one can they can stretch their ideas as far as they need to and express creativity. This also helps to reach out to the root cause of the agenda of map and take potential action to resolve the problem. Drawing map and branching out association is considered to be therapeutic. Merits of mind mapping would include fostering personal growth, reduces anxiety, helps in letting go and relaxing.

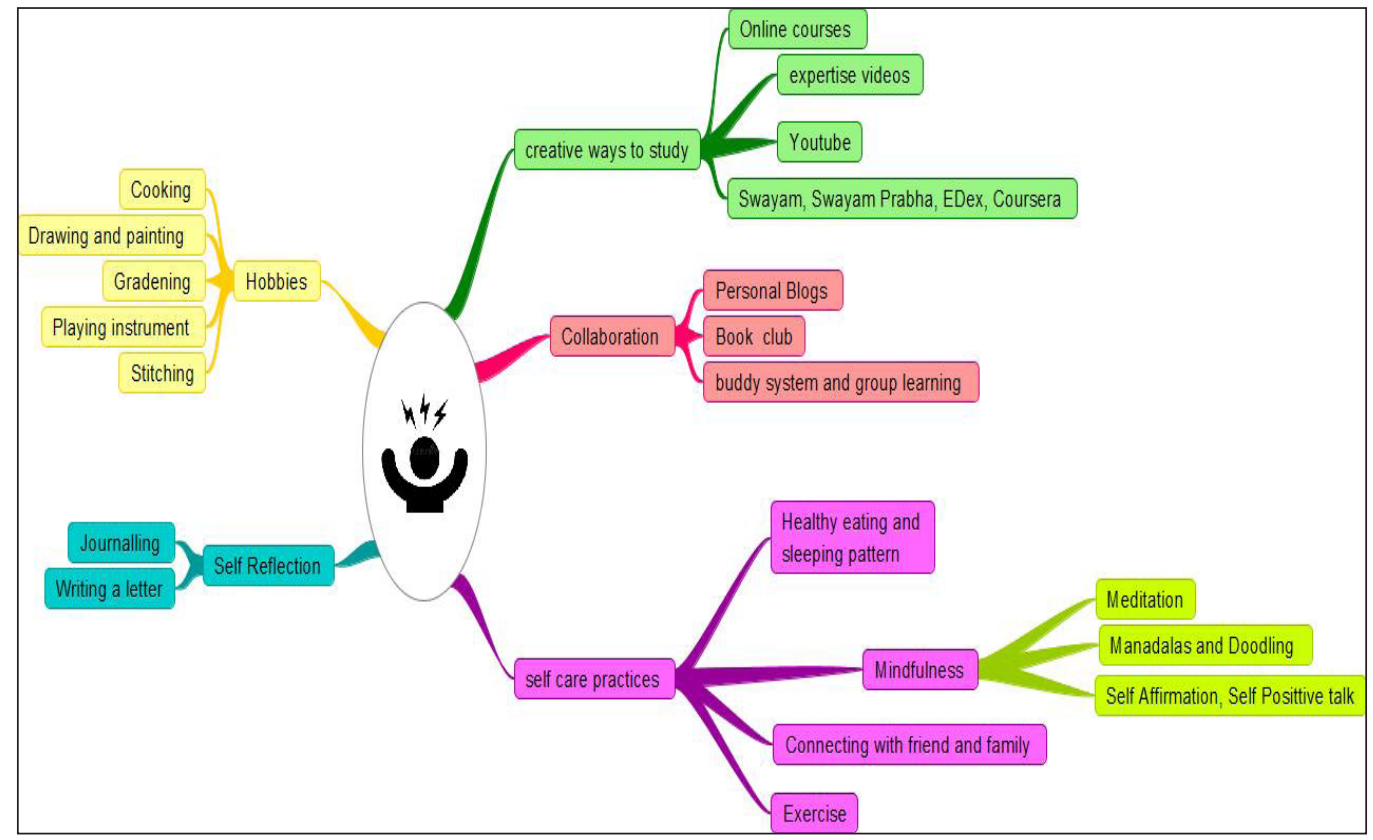

Fig. 1: Mind Mapping of Coping with Stress for Students

Students can gather thoughts in form of visual mind map. This helps in organizing the free-flowing thoughts into something meaningful. It is place where the ideas can be stored and revisited later in order to gain inspiration. 
After jotting down the feelings and causes of stress on the map. It gives a feeling of being in control and shows the path in which the problems could be tackled. Later the map could be broken into smaller chunks and each section could be addressed separately one step at a time. Student could also mark red flags on the map as an indicator on thoughts and ideas which needs to avoided. The following mind map is framed as Fig. 1 to help the students to cope up with stress during lock down period of COVID-19.

\section{Creating Creative ways to study}

Advent of lockdown has made the schools and college to bring classes online, which can be new area for students and might take time to adapt to the scenario. They can take this opportunity to study in a fun way in order to enjoy visual and auditory learning like enrolling them selves with various online short -term courses available for interesting topics, watch expertise videos on relevant educational topics, explore Open Educational Recourses on the subject they are fascinated with and subscribe to you tube channels which would cater their hobbies e.g. Online painting and gardening tutorial etc. These techniques could be used to balance out their monotonous study routine of online classes with something creative which is less boring.

\section{Revisit past hobbies}

Even though thinking about virus is taxing still to look on the brighter side it has given us a lot of time in hand which could be utilised in an interesting and productive manner. Students have fixed routine and busy schedule to follow hence they might not have the time to spend some time on things which they like to do. Nevertheless, they can use this golden hour to start which they discontinued in the past. Do what the heart wants, experiment different things and turn adversities into opportunities.

Starting a hobby helps in spending tome productively and is comparatively stress freeway. Engaging both physically and mentally on something you love provides motivation and joy. These positive feeling will help you feel happy and stress free and occupied which helps in promoting positive overall sense of well-being.

Start reading book you wanted to complete.

Try different recipes and start cooking as it is found to be therapeutic ${ }^{[11]}$.

Painting your thoughts or watering plants.

The authors ${ }^{[12]}$ highlighted the effect of leisure activities such as various kind of hobbies like reading, playing etc. on students perceived academic stress. The resulted showed that lower perceived academic stress was exhibited when there was greater participation in leisure activities.

\section{Collaboration}

Lock down has decreased socialization. But students can still find like minded people with similar 
P. Sahitya

interest and start a book club where they can discuss about the books they have discussed or cooking group where each one tries new dishes and shares recipes.

\section{Self-Reflection}

Stress is a time where thoughts are clouded leading to a tunnel vision. Journalizing thoughts or creating a blog can help to reflect on the thoughts in future and measure the progress you have made and gain motivation from it. It also helps in venting out pent feelings.

Write down the event and analyse root cause of why it happened.

Write how you felt about it.

Write what could have been improved.

The study ${ }^{[13]}$ shows that gratitude journaling helped the students to have heightened level of meaning fullness and engagement in the classroom.

\section{Self -Care Techniques}

At the time of stress its mandatory to take good care of themselves as this enhances positivity and confidence to tackle any situation. Few steps which could be considered are:

Exercise: Exercise is beneficial for both mind and body as endorphins known as the good hormones are released which helps in reducing tension and allows the mind to concentrate on things other than worries and concerns.

Mindfulness: Charellote quoted that "When we are stressed our minds sometimes behave in ways that hinder rather than help. Rather than ruminating over the problem, catastrophising about the future or critically analysing your latest attempts, take time out to focus your mind on something relaxing and positive". Mindful activities will include activities like meditation where the focus is on breathing or drawing mandala's or doodles. Similar studies [14] attempted that the short term effect on a 8 week mediation- based reduction of stress intervention on medical students and the results showed that there was reduction in overall psychological stress and depression, also there was increase in empathy levels

Healthy Eating and Managing Sleep pattern: Stress can often interrupt sleep and eating pattern so students could have a balanced meal at home. And try to maintain good sleep pattern by relaxing themselves as much as possible and by avoiding by avoiding screen time as much as possible. Mental Health Department of WHO advised ${ }^{[15]}$ that "During times of stress, pay attention to your own needs and feelings. Engage in healthy activities that you enjoy and find relaxing. Exercise regularly, keep regular sleep routines and eat healthy food".

Connecting with Friends and Family: Even the situation of isolation students could try to be connected with friend and family from social networks and try to keep this as a part of their routine. Stay connected 
via e-mail, social media, video conference, video calls and voice calls. These helps maintain bonds with people and also relaxing.

To execute the objective number (iv), to investigate the use of proposed framework for mind map with the help of case studies. Three cases were identified who were willing to apply this mind up technique to cope up with their stress. The case studies are as follows :

\section{CASE STUDIES}

Subject $\mathrm{H}$ working in corporate sector after completing her MBA. Subject never experienced work from home during her career. Subject felt difficult to accommodate to the routine and was getting hampered as there was no definite time table to follow.

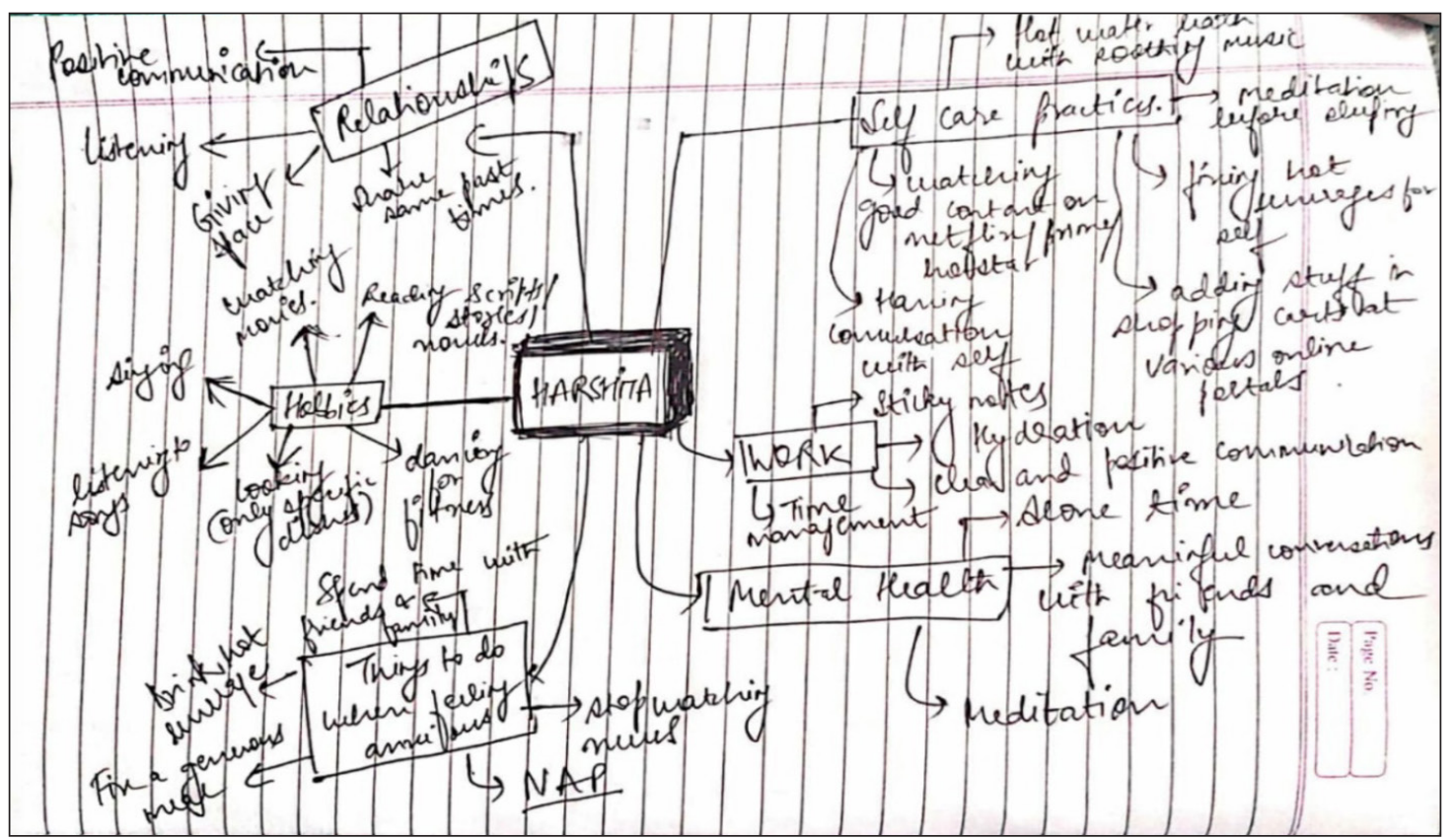

Fig. 2: Mind Map created by subject $H$

Subject had abundance of time but didn't know how to utilise it in a systemic manner. This caused stress as her mind was clouded with a variety of flowing thoughts which included thoughts about her relationships, family and work. Subject wanted to channelize her stream of thoughts in different categorization. The Researcher suggested making a mind map to the subject. And taught her how to make it. After a week researcher asked the subject on how effective was the mind map working. Subject replied that she felt contended with her mind map as she can visualise all her thoughts at single time in front of her. This helped her to branch out various ideas and thoughts which works for her according her sub categories on the map. The mind map created by subject $\mathrm{H}$ is given in the Fig. 2. 
Subject $\mathrm{R}$, is a medical student in college $1^{\text {st }}$ year. In her schooling days she was under institutional time table which had definite time for each subject but after coming to college she faced stress because it took her time to accommodate to new environment, new education pattern adjusting to college time table and making new friends was a struggle for her. Later when college was announced to be under lockdown she felt lose of freedom and felt stuck because studying in online in front of desktop for hours was difficult for her she felt frustrated and lost her sense of time and wanted to organise herself. The researcher suggested use of mind map to her. Now the subject is happy as she has scheduled her tasks in a particular manner and she feels organized and is not mixed up with tasks she has clear vision as to what needs to be done next. The highlights of her mind map are online classes, assignments, online exams and management of food and diet. The mind map created by subject $\mathrm{R}$ is given in the Fig. 3 .

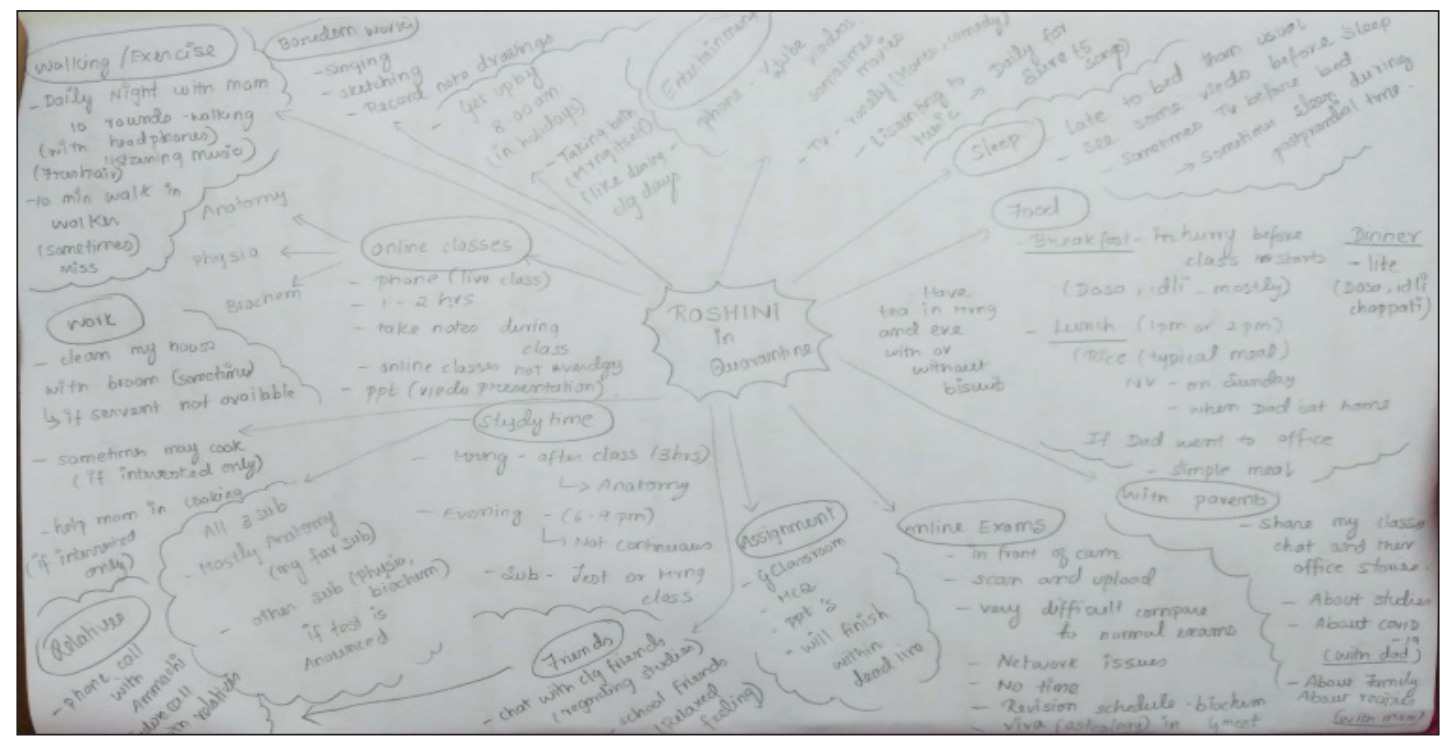

Fig. 3: Mind Map created by subject $R$

Subject $\mathrm{T}$ is a pre schoolteacher who was facing difficulty to cope up with stress. As education system has turned to online platform and its tough for pre school children to take online classes hence subject is under anxiety that she might lose her job. And COVID-19 had added extra anxiety for her because of number of COVID cases increasing day by day and uncertainty about future made the subject confused and helpless. The researcher introduced the concept of mind map to her and asked the subject to map out the possible ways that the subject thinks might help her when in stress and follow them as per her convenience. Subject liked her map and said it helped her as there were several activities she wants to follow like following her hobbies, self-care activities, online courses etc but under stress she is always under a fix. But with help of mind map she could visualise all her activities which made the selection of activity suitable for her easier. The mind map created by subject $\mathrm{T}$ is given in the Fig. 4 . 


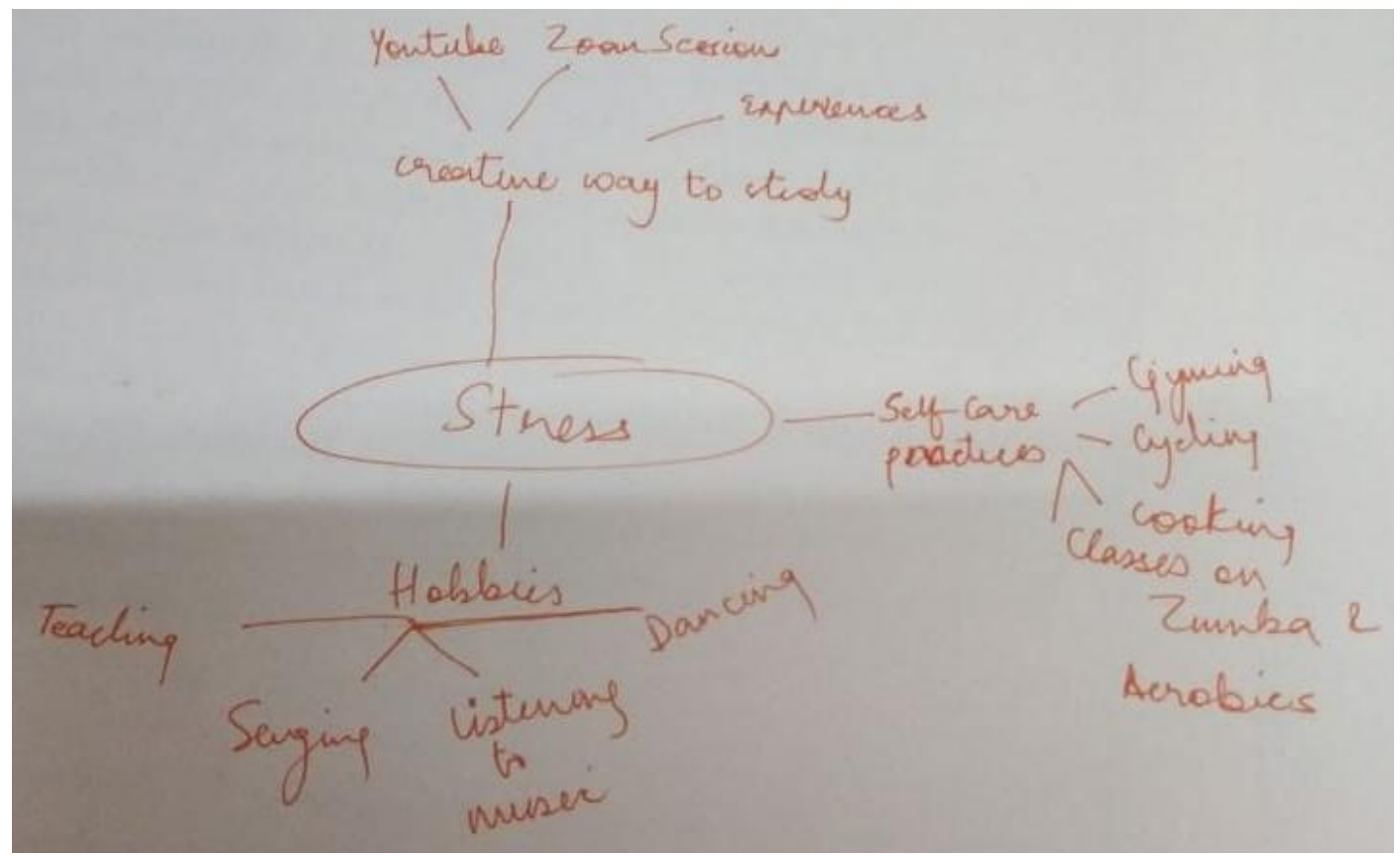

Fig. 4: Mind Map created by subject T

\section{CONCLUSION}

Stress is a common feature shown by every individual and it could be kept in control by making few amendments in our lifestyle. Organizing thoughts would help us in having a clear vision and move towards our goals easily. Setting peace of mind as the highest goal and organizing life around it would help to have a command over stress and build resilience against it. To cope up with the stress the thoughts could be arranged logically using mind map to perform more tasks. Mind mapping is not only useful for students but it will help teachers and parents to provide effective support to the learners by designing a map full of clarity and organised thoughts. During pandemic the researcher has only investigated with three case studies, this could be further experimented to standardize the framework for the better practice in future.

\section{REFERENCES}

1. Neumann, G., Noda, T. and Kawaoka, Y. 2009. Emergence and pandemic potential of swine-origin H1N1 influenza virus. Nature, 459(7249): 931-939.

2. Girard, M.P., Tam, J.S., Assossou, O.M. and Kieny, M.P. 2010. The 2009 A (H1N1) influenza virus pandemic: A review. Vaccine, 28(31): 4895-4902. 
M Sahitya

3. Sinha, B.K., Willson, L.R. and Watson, D.C. 2000. Stress and coping among students in India and Canada. Canadian Journal of Behavioural Science/Revue canadienne des sciences du comportement, 32(4): 218.

4. Brougham, R.R., Zail, C.M., Mendoza, C.M. and Miller, J.R. 2009. Stress, sex differences, and coping strategies among college students. Current Psychology, 28(2): 85-97.

5. Percival, J. 2003. Know your mind. Nursing Standard (through 2013), 17(41): 24.

6. Trevino, C. 2005. Mind mapping and outlining: comparing two types of graphic organizers for learning seventhgrade life science (Doctoral dissertation).

7. Zampetakis, L.A., Tsironis, L. and Moustakis, V. 2007. Creativity development in engineering education: The case of mind mapping. Journal of Management Development.

8. Tuckey, M.R., Searle, B., Boyd, C.M., Winefield, A.H. and Winefield, H.R. 2015. Hindrances are not threats: Advancing the multidimensionality of work stress. Journal of Occupational Health Psychology, 20(2): 131.

9. Crisis Intervention and Suicide Prevention Centre of British Columbia. 2010. Coping with Stress. Retrieved April 16, 2020, from www.crisiscentre.bc.ca/get-help/coping-withstress/.

10. Crystal. 2019. How to use Mind Mapping for Stress Management, http://ladywellloved.com/2019/09/05/how-touse-mind-mapping-for-stress-management-a-womans-guide/, retrieved on June 16,2020

11. Chris Langrill, News and Community. 2020. Stay-home order offers opportunity to revisit old hobbies, start new ones - or just take a break https://www.stlukesonline.org/blogs/st-lukes/news-and-community/2020/apr/just-takea-break, retrieved on June 21,2020

12. Ragheb, M.G. and McKinney, J. 1993. Campus recreation and perceived academic stress. Journal of College Student Development.

13. Flinchbaugh, C.L., Moore, E.W.G., Chang, Y.K. and May, D.R. 2012. Student well-being interventions: The effects of stress management techniques and gratitude journaling in the management education classroom. Journal of Management Education, 36(2): 191-219.

14. Shapiro, S.L., Schwartz, G.E. and Bonner, G. 1998. Effects of mindfulness-based stress reduction on medical and premedical students. Journal of Behavioral Medicine, 21(6): 581-599.

15. Stress Management Guidelines. 2020. http://www.ima-india.org/ima/pdfdata/COVID-19/Stress-Management.pdf, retrieved on 30-June-2020. 